\title{
Developed and validated stability indicating HPLC method for the determination of epirubicin in bulk drug, marketed injection and polymeric nanoparticles
}

\author{
Mohammad Tariq ${ }^{1}$, Shindu Thomas ${ }^{2}$, Anu Singh ${ }^{3}$, Sushama Talegaonkar ${ }^{2,4^{*}}$ \\ ${ }^{1}$ Tech Observer India Private Limited, New Delhi, India, ${ }^{2}$ Department of Pharmaceutics, School of Pharmaceutical Education \\ and Research, (SPER), Jamia Hamdard, New Delhi, India, ${ }^{3}$ Dabur Research Foundation, Sahibabad, Ghaziabad, India, \\ ${ }^{4}$ Department of Pharmaceutics, Delhi Pharmaceutical Sciences and Research University (DPSRU), Pushp Vihar, New Delhi, \\ India
}

\begin{abstract}
Present work is aimed to develop a simple, sensitive, robust and reliable HPLC method for routine quality control of epirubicin (EPI) in bulk drug, marketed injections and polymeric nanoparticles. Separation was carried out by $\mathrm{C} 18$ column. Isocratic elution was carried out using mobile phase A: $0.16 \%$ o-phosphoric acid solution, B: acetonitrile and methanol mixture $(80: 20, \mathrm{v} / \mathrm{v})$ in the ratio of 60:40 (A: B) while the flow rate was maintained at $1 \mathrm{~mL} / \mathrm{min}$. Analyses were performed at $233.5 \mathrm{~nm}$ using PDA detector. Excellent linear relationship was observed between peak-area versus drug concentration in the range of $1.0-100.0 \mu \mathrm{g} / \mathrm{mL}\left(\mathrm{r}^{2}, 0.999\right)$. Developed method was found to be sensitive (Limits of detection and quantification were found to be $\sim 8 \mathrm{ng} / \mathrm{mL}$ and $\sim 25 \mathrm{ng} / \mathrm{mL}$, respectively), precise (RSD $<1.0 \%$, for repeatability and $<2.0 \%$ for intermediate precision, within acceptable ranges of precision), accurate (recovery in different dosage form, $94.65-100.26 \%$, within acceptable range, 80-120\%), specific and robust ( $\% \mathrm{RSD}<2$, for system suitability parameters). Stress-induced degradation studies demonstrated that method can suitability be applied in the presence of degradants. Developed method has been successfully applied for the determination of entrapment efficiency, drug loading, in vitro release profile, in vitro permeation studies as well as stability assessment of polymeric nanoparticles.
\end{abstract}

Keywords: Epirubicin. HPLC. Polymeric nanoparticles. Quality control. Forced degradation.

\section{INTRODUCTION}

Epirubicin (10-(4-amino-5-hydroxy-6-methyloxan-2-yl)oxy-6,8,11-trihydroxy-8-(2hydroxy acetyl)1 -methoxy-9,10-dihydro-7H-tetracene-5,12-dione) is an anthracycline anticancer agent which is used for the treatment of node positive breast cancer, ovarian cancer, gastric cancer, lung cancer and lymphomas (Neil, 2006). Epirubicin is obtained by chemical transformation of a substance produced by certain strains of Streptomyces peucetius (Neil, 2006). It acts by forming a complex with DNA by intercalation into nucleotide base pairs thus hindering DNA and RNA synthesis (Omrod et al., 1999). It is favoured over doxorubicin as it is found to be less

\footnotetext{
*Correspondence: S. Talegaonkar. Delhi Pharmaceutical Science and Research University, New Delhi, India. Phone: +91-9818453518. E-mail: stalegaonkar@gmail.com
}

toxic at equimolar dose which may be due to the different spatial orientation of the hydroxyl group at the 4' carbon of the sugar moiety results in opposite chirality which leads to its faster elimination and reduced toxicity (Neil, 2006; Sweetman, Martindale, 2007). It is available as intravenous injection but due to sudden rise in the blood level and rapid elimination often to sub therapeutic levels necessitates frequent dosing leading to a serious adverse effect. Hence, we formulated polymeric nanoparticles delivery system, to achieve controlled drug release, which will not only limit the side effects but also help in reducing dose and dosing frequency. With the advancement in nanotechnology-based delivery system and their complex pharmacokinetics requires a stringent quality control of these dosage forms to maintain its safety and efficacy. At present, EPI is being used extensively in clinical practice and therapy. Therefore, accurate and validated analytical method is required for quantitative analyses of EPI in 
bulk drug, marketed injection, polymeric nanoparticles, in-vitro as well as in biological samples. Several analytical methods such as LC/MS-MS (Wall et al., 2007; Sottani et al., 2009), LC equipped with UV (Dodde et al., 2003; Badea et al., 2005), fluorescence (Dine et al., 1990), and electrochemical detector (Ricciarello et al., 1998) have been reported so far for analysis of EPI in biological fluids. These analytical methods (LCMS, Fluorescence detection) are more sensitive and accurate, however expensive, hence, limit their utility in the routine quality control of pharmaceutical dosage forms. In addition, no method has been reported so far for quantitative analysis of epirubicin in polymeric nanoparticles.

In the given study, a simple, rapid, sensitive and accurate HPLC-UV method is developed which is capable of detecting and quantifying minute quantity of drug accurately and precisely with a short run time in bulk drug, marketed formulation, polymeric nanoparticles, and in-vitro studies sample which may be further extended to in-vivo biological fluids such as plasma, serum etc. Here, the method is validated for accuracy, precision, selectivity, sensitivity and various other validation parameters as per ICH guidelines.

\section{MATERIAL AND METHODS}

\section{Instrumentation and chromatographic conditions}

The liquid chromatographic system e2695 separation module (Waters Alliance, Milford, MA, USA) equipped with a gradient flow control pump, online solvent degasser, auto-sampler, PDA detector 2998, column manager and pre-column heater was used for the analysis. All the parameters of HPLC were controlled by LC solutions software Empower 2. Chromatographic separations were obtained by using Purosphere ${ }^{\circledR} \mathrm{C} 18(5 \mu \mathrm{m}, 250 * 4.6 \mathrm{~mm})$ column, which was maintained at $30^{\circ} \mathrm{C}$. Ten microliters of sample was injected into HPLC system. Isocratic elution was carried out using mobile phase which is the mixture of aqueous phase $(A, 60 \mathrm{v} / \mathrm{v})$ and organic phase $(B, 40 \mathrm{v} / \mathrm{v})$. Aqueous phase (A) comprising of $0.16 \%$ O-Phosphoric acid solution while organic phase (B) comprising of acetonitrile and methanol mixture (80:20). The flow rate was maintained at $1 \mathrm{~mL} / \mathrm{min}$. The mobile phase was filtered through $0.45 \mu \mathrm{m}$ filter (Sartorius, Germany) and deaerated for $15 \mathrm{~min}$ by sonication before injecting into the system and column was allowed to equilibrate for $20 \mathrm{~min}$ with the mobile phase. All samples were analyzed at wavelength of $233.5 \mathrm{~nm}$ for a total run time of $12 \mathrm{~min}$. Data acquisition and data handling were performed by Empower Software v2.0. Developed method was validated for parameters like precision, accuracy, robustness, specificity, sensitivity, linearity as described in ICH guidelines (ICH, 2005).

\section{Method development}

\section{Preparation of stock and standard solutions}

Ten milligrams of EPI was accurately weighed and transferred to a $10 \mathrm{~mL}$ volumetric flask and dissolved in methanol followed by sonication and subsequently filtered through $0.45 \mu \mathrm{m}$ filter to get a stock solution, $1 \mathrm{mg} / \mathrm{mL}$. Stock solution was further diluted to obtain the required concentrations $(1-100 \mu \mathrm{g} / \mathrm{mL})$ before injecting into the system for analyses. Quality control samples at three levels, low $(2 \mu \mathrm{g} / \mathrm{mL})$, intermediate $(10 \mu \mathrm{g} / \mathrm{mL})$ and high $(50 \mu \mathrm{g} / \mathrm{mL})$ were also prepared in the same way.

\section{Method validation}

The developed method was validated for linearity range, precision, accuracy, robustness, limit of detection (LOD) and limit of quantification (LOQ) as per ICH guidelines (ICH, 2005).

\section{System suitability}

For the assessment of system suitability, $10 \mu \mathrm{L}$ of epirubicin solution $(10 \mu \mathrm{g} / \mathrm{mL}, \mathrm{n}=6)$ were injected and system suitability parameters like retention time, peak area, theoretical plates and tailing factor were calculated and compared with standard accepted values.

\section{Linearity}

A 7-point calibration curve was constructed in a concentration range of $1-100 \mu \mathrm{g} / \mathrm{mL}$ for linearity. The mean peak area of epirubicin was plotted against its concentration and linear least square regression analysis was performed.

\section{Limit of detection and limit of quantification}

Limit of detection (LOD) and limit of quantification (LOQ) were determined based on the signal to noise ratios $(\mathrm{s} / \mathrm{n})$ using analytical responses of three and ten times of the background noise, respectively using the following equation, $\mathrm{s} / \mathrm{n}$ ratio was calculated through Empower software version 2 (Warsi et al., 2011; Tariq et al., 2015a).

$$
\begin{aligned}
L O D & =3.3 \times \frac{\mathrm{s}}{\mathrm{n}} \\
L O Q & =10 \times \frac{\mathrm{s}}{\mathrm{n}}
\end{aligned}
$$

\section{Precision}

Precision of the methods was determined in terms of 
intra-day and intermediate precision. Intra-day precision (Repeatability) of developed method was determined by analyzing quality control samples $(2 \mu \mathrm{g} / \mathrm{mL}, 10 \mu \mathrm{g} / \mathrm{mL}$, $50 \mu \mathrm{g} / \mathrm{mL}$, each 6 replicates) using identical test material, identical analytical method and similar experimental conditions over a short period. Results were analyzed by identical evaluation method. Intermediate precision was determined on different days, rest of the conditions was followed as described for intra-day precision. Intra-day and intermediate precision were expressed as relative standard deviation (RSD, \%).

\section{Accuracy}

Accuracy of the developed method was assessed by assaying 9 samples. Test samples $(100 \mu \mathrm{g} / \mathrm{mL}$ claimed amount) were spiked with 3 levels of claimed amount i.e. low (LQC, $50 \mu \mathrm{g} / \mathrm{mL}$ ), medium (MQC, $100 \mu \mathrm{g} / \mathrm{mL}$ ) and high (HQC, $150 \mu \mathrm{g} / \mathrm{mL}$ ). Accuracy was determined as following and expressed in terms of $\%$ recovered;

$$
\text { Recovery }(\%)=\frac{\text { Experimentally determined concentration }}{\text { Theoretical concentration }} \times 100
$$

\section{Robustness}

Robustness of method was determined by changing $\mathrm{pH}$ of mobile phase, column temperature and column manufacturer. The robustness of methods was expressed as RSD (\%) for system suitability parameters like peak areas, RT, and peak tailing.

\section{Forced degradation studies}

The specificity of the method was determined by exposing drug solution of known concentration $(100 \mu \mathrm{g} / \mathrm{mL})$ to different conditions like acidic $(0.1 \mathrm{M} \mathrm{HCl}$ for $24 \mathrm{~h})$, basic $(0.1 \mathrm{M} \mathrm{NaOH}$ for $24 \mathrm{~h})$, oxidizing $\left(30 \% \mathrm{H}_{2} \mathrm{O}_{2} \mathrm{v} / \mathrm{v}\right.$ for $24 \mathrm{~h}$ ), photolytic degradation (for $24 \mathrm{~h}$ ), and thermal stress at $50{ }^{\circ} \mathrm{C}$ for $24 \mathrm{~h}$ (Tariq et al., 2014). The resulting solutions were diluted and processed accordingly and analyzed for the drug peak as well as degradation product.

\section{Applications of method}

Epirubicin loaded poly-lactide-co-glycolic acid nanoparticles (EPI-NPs) were prepared by double emulsion solvent evaporation as described in our previous report (Tariq et al., 2014).

\section{Determination of entrapment efficiency and drug loading}

Entrapment efficiency and drug loading was calculated as following;

$$
\begin{gathered}
\text { Entrapment efficiency }(\%)=\frac{\text { Amount of drug loaded into the NPs }}{\text { Total amount of drug taken }} \times 100 \\
\text { Drug loading }(\%)=\frac{\text { Amount of drug loaded into the NPS }}{\text { Total amount of formulation }} \times 100
\end{gathered}
$$

\section{In vitro Release Profile}

In vitro release study was performed by dialysis bag method and compared with free drug solution. EPI ( $2 \mathrm{mg}$ ) and EPI-NPs (equivalent to $2 \mathrm{mg}$ EPI) were suspended into $5 \mathrm{~mL}$ dissolution media and poured into dialysis bag ((MWcut off of 8-10 kDa, Spectra/Por $\left.{ }^{\circledR}\right)$ and subsequently dialysis bag was dipped into $50 \mathrm{~mL}$ of dissolution media. Study was carried at $37^{\circ} \mathrm{C}$ and $100 \mathrm{rpm}$ under magnetic stirrer. Samples were withdrawn at regular time interval and analyzed by HPLC.

\section{In vitro permeation study}

EPI is a substrate for both P-glycoprotein (P-gp) and cytochrome P450 (CYP 450), and also highly hydrophilic in nature hence elicits poor oral bioavailability. Therefore, epirubicin loaded PLGA NPs were developed to improve oral bioavailability. Developed formulation was evaluated for in-vitro permeation profile by using Caco- 2 cell line model and intestinal gut sac method as previously reported (Tariq et al., 2015b).

For cellular transport study, cells ( $10^{5} /$ insert) were grown on polycarbonate membrane filters with $0.4 \mu \mathrm{m}$ pore size and $1.12 \mathrm{~cm} 2$ growth area. Only cell monolayers with TEER values over $300 \Omega \mathrm{cm}^{2}$ were included in the study. Transport of EPI-S and EPI-NPs was studied in the apical to basal direction. For the purpose, $0.5 \mathrm{~mL}$ of test solutions (diluted with serum free growth media) were added to apical side whereas $1.5 \mathrm{~mL}$ of serum free growth media was added to basolateral side. At each time point, $0.2 \mathrm{~mL}$ samples from basolateral side were withdrawn and stores at $-20^{\circ} \mathrm{C}$.

For intestinal permeation study, Ileum $(5-7 \mathrm{~cm})$ was washed with saline followed by ligation of on end while other end was mounted on assembly use to conduct the study. Ileum sac was filled with EPI-S solution ( $1 \mathrm{~mL}$, $100 \mu \mathrm{g} / \mathrm{mL}$ ) or EPI-NPs suspension (equivalent to $100 \mu \mathrm{g}$ of EPI in $1 \mathrm{~mL}$ ) and suspended into pre-warmed $\left(37 \pm 0.5^{\circ} \mathrm{C}\right)$ and pre-oxygenated Tyrode's buffer $(10 \mathrm{~mL})$. Samples $(0.5 \mathrm{~mL})$ were withdrawn defined time intervals, $15,30,45,60,75,90 \mathrm{~min}$ and stored at $-20{ }^{\circ} \mathrm{C}$.

Samples of cellular and intestinal transport studies were analyzed by HPLC and permeation data was expressed as flux (Jss, $\mu \mathrm{g} / \mathrm{cm} 2 / \mathrm{h}$ ).

\section{Stability studies of EPI-NPS as per ICH guidelines}

Stability study of (EPI-NPS) was carried out as per ICH Q1A (R2) guidelines (ICH, 2003). Formulation was 
subjected to $5 \pm 3{ }^{\circ} \mathrm{C}$ (long term study) and $25 \pm 2{ }^{\circ} \mathrm{C}$ and $60 \pm 5 \% \mathrm{RH}$ (accelerated storage condition) for a period of six months. Samples were analyzed at regular time intervals $0,30,60,90$, and 180 days for the change in their drug content by HPLC.

\section{RESULTS AND DISCUSSIONS}

\section{Method development}

In the present study, various parameters like column, mobile phase composition, mobile phase ratio, flow rate and its $\mathrm{pH}$ were optimized to obtain a good peak shape with high resolution, symmetry and reproducibility. Columns such as Supelco ${ }^{\circledR}$ and Purosphere ${ }^{\circledR}$ were used and the best peak was obtained with Purosphere ${ }^{\circledR}$. Different mobile phases were tried such as acetonitrilewater, methanol-water, and mixture of acetonitrile: methanol and water. As the epirubicin hydrochloride is an ionizable compound hence best peak was expected at lower $\mathrm{pH}$ therefore $\mathrm{pH}$ adjusted $(\mathrm{pH} 3)$ with phosphoric acid which resulted in best peak with good symmetry and high resolution. Thus, best peak and low retention time was obtained with $0.16 \%$ aqueous o-phosphoric acid solution (A) and mixture of acetonitrile: methanol, 80:20 $\mathrm{v} / \mathrm{v}$ (B) when isocratic elution was carried out at the mobile phase ratio of 60:40 (A:B). The flow rate was maintained at $1 \mathrm{~mL} / \mathrm{min}$. All the above optimized parameters produced a peak with good shape and very short retention time, $4.52 \pm 0.3 \mathrm{~min}$ (Figure 1) which is the lowest retention time of all the methods developed so far in our belief. However, the total run time was $12 \mathrm{~min}$, giving an additional time for complete elution of excipients and degradation products to avoid carry over peak in the next injections.

\section{Method validation}

\section{System suitability}

System suitability was evaluated by six replicated injections at a concentration of $10 \mu \mathrm{g} / \mathrm{mL}$ and system suitability parameters were summarized in Table I. All the parameters met the acceptance criteria (USP) and relative standard deviation for individual parameters was found to be less than $1 \%$.

\section{Linearity}

The linearity of an analytical method is its capability (within a given range) to achieve test results which are directly proportional to the concentration (amount) of analyte in the sample. Linearity of method was determined by calibration plot constructed between peak area and analyte concentration (Table II and Figure 2). The linear regression data over the concentration range of $1-100 \mu \mathrm{g} / \mathrm{mL}$ was found to be within $95 \%$ confidence limit with a correlation coefficient $\left(r^{2}\right), 0.999$ which confirmed the excellent linearity of developed method in the range (Table II).

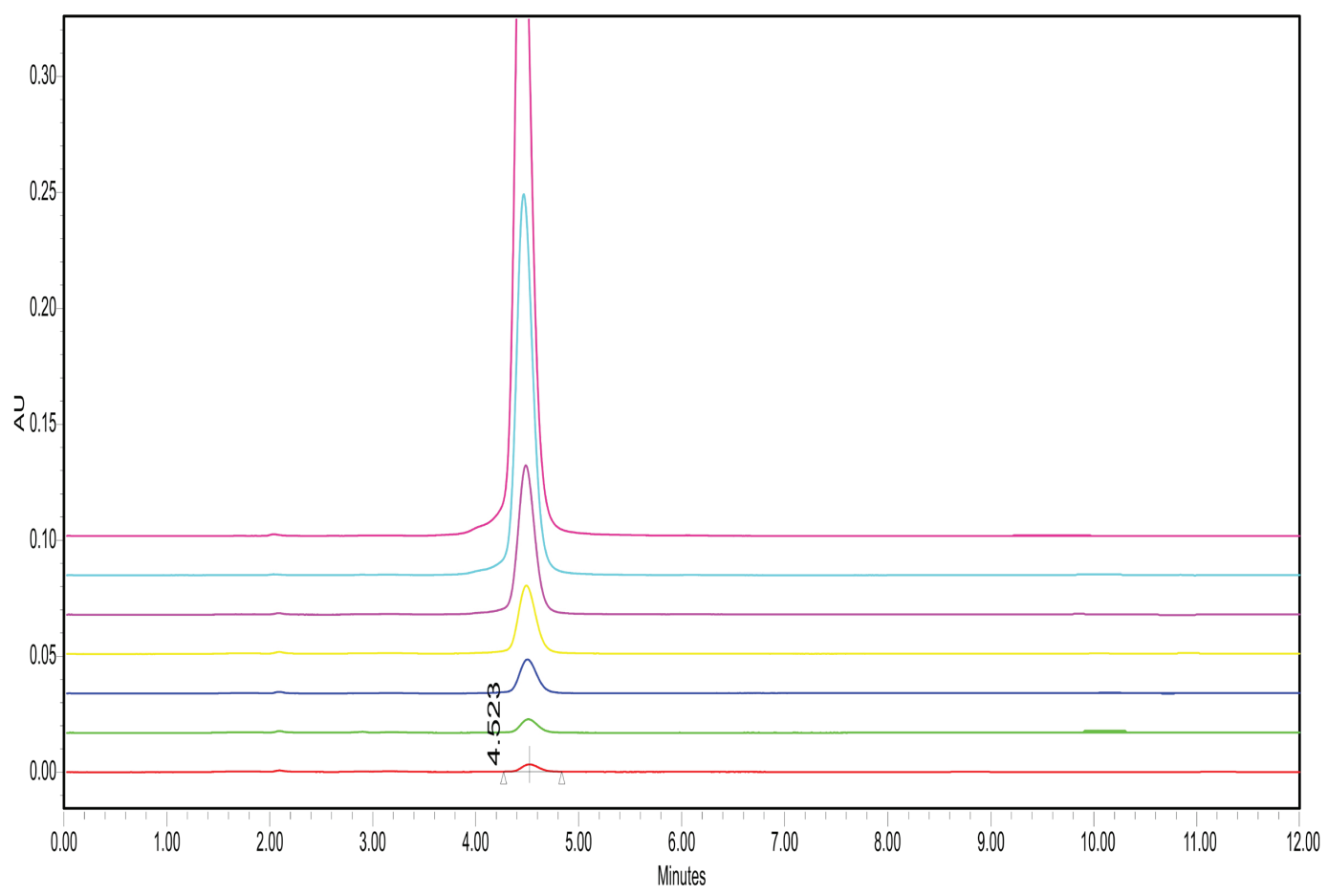

FIGURE 1 - Overlay of representative chromatograms of epirubicin. 
TABLE I - System suitability $(\mathrm{n}=6)$

\begin{tabular}{lcccc}
\hline & Peak area & RT & UPS tailing & HETP \\
\hline & 348533 & 4.548 & 0.94 & 3223 \\
& 350123 & 4.503 & 0.92 & 3312 \\
& 352437 & 4.528 & 0.93 & 3245 \\
& 345673 & 4.539 & 0.94 & 3284 \\
& 349896 & 4.511 & 0.92 & 3305 \\
& 351001 & 4.55 & 0.92 & 3213 \\
Mean & 349611 & 4.53 & 0.93 & 3263.7 \\
SD & 2320.85 & 0.02 & 0.01 & 42.49 \\
RSD & 0.66 & 0.43 & 1.06 & 1.30 \\
\hline
\end{tabular}

TABLE II - Linear regression data for calibration plots

\begin{tabular}{lc}
\hline Parameters & Regression Values \\
\hline Linearity range & $1-100 \mu \mathrm{g} / \mathrm{mL}$ \\
Regression equation & $\mathrm{Y}=37712 \mathrm{X}-27028$ \\
Correlation coefficient $\left(\mathrm{r}^{2}\right)$ & 0.999 \\
Slope & 37712 \\
Intercept & -27028 \\
\hline
\end{tabular}

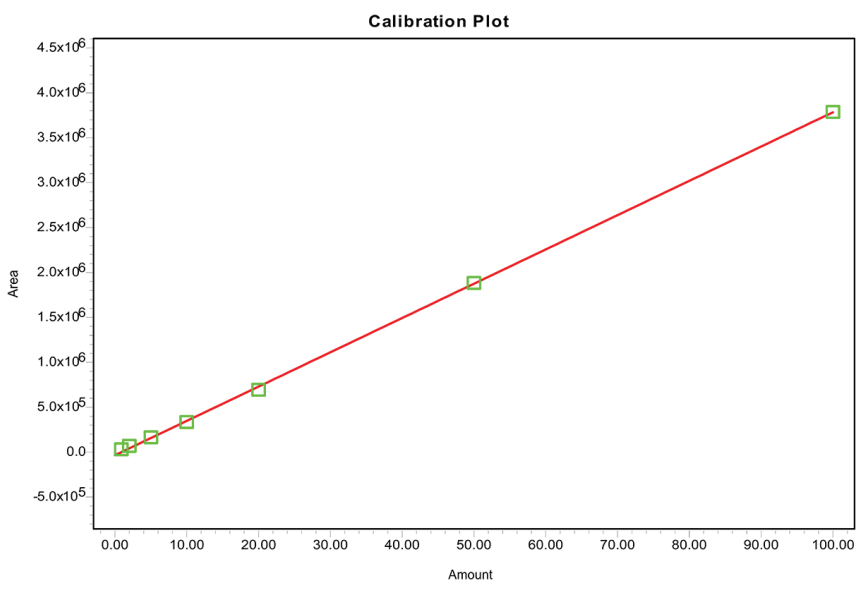

FIGURE 2 - Calibration plot of epirubicin hydrochloride (concentration range $1-100 \mu \mathrm{g} / \mathrm{mL}$ ).
Limit of detection and limit of quantification

Kurbanoglu et al. (2013) reported LOQ for epirubicin $27 \mathrm{ng} / \mathrm{mL}$ and LOD and LOQ were found to be $8 \mathrm{ng} / \mathrm{mLand} 25 \mathrm{ng} / \mathrm{mL}$ for our developed method which indicated that the developed method is more sensitive than previous one. Sensitivity of any analytical method is expressed in term of limit of detection and limit of quantification (LOD and LOQ). LOD represents the lowest amount of analyte that can be detected but not quantified precisely, while LOQ represents the quantity of analyte which can be quantified accurately and precisely. Low values of LOD $(8 \mathrm{ng} / \mathrm{mL})$ and LOQ $(25 \mathrm{ng} / \mathrm{mL})$ reflect that the developed method is sensitive.

\section{Precision}

Table III summarizes repeatability and intermediated precision which were found to be $<1 \%$ and $<2 \%$, respectively. Both repeatability and intermediated precision were within the acceptance limit (ICH, 2005), thus developed method is said to be precise. Precision represents random error i.e. errors which occur at any point of analysis from sampling to calculation. It can be determined at 3 levels i.e. repeatability (Intra-day precision $1^{\text {st }}$ level $)$, intermediate precision $\left(2^{\text {nd }} l\right.$ level) and reproducibility ( $3^{\text {rd }}$ level). Repeatability is determined over a short period of time under similar test concentration, materials, method and experimental conditions while intermediate precision is determined on different days, by different analysts using different equipment. Reproducibility represents inter-laboratory precision, usually not considered as a part of analytical validation until unless developed method is meant for analytical transfers. Hence, precision was determined in terms of repeatability and intermediate precision only.

\section{Accuracy}

Accuracy of a method is defined as closeness between the experimentally measured value and the true value. Difference between experimentally measured value and true value represents the systematic error or bias of a method in the presence of excipients/formulation components. Accuracy of method was determined as \% recovered

TABLE III - Intra-day and inter-day precision $(\mathrm{n}=6)$

\begin{tabular}{ccccc}
\hline \multirow{2}{*}{$\begin{array}{c}\text { Theoretical Conc. } \\
(\boldsymbol{\mu g} / \mathbf{m L})\end{array}$} & \multicolumn{2}{c}{ Intra-day precision } & \multicolumn{2}{c}{ Inter-day precision } \\
\cline { 2 - 5 } & Mean Conc. $(\boldsymbol{\mu g} / \mathbf{m L})$ & \% RSD & Mean Conc. $(\boldsymbol{\mu g} / \mathbf{m L})$ & \% RSD \\
\hline $2(\mathrm{LQS})$ & $2.094 \pm 0.01$ & 0.48 & $2.08 \pm 0.03$ & 1.63 \\
$10(\mathrm{MQS})$ & $9.87 \pm 0.05$ & 0.55 & $9.88 \pm 0.135$ & 1.36 \\
$50(\mathrm{HQS})$ & $49.11 \pm 0.215$ & 0.43 & $49.28 \pm 0.50$ & 1.0 \\
\hline
\end{tabular}


TABLE IV - Accuracy as $\%$ recovery $(\mathrm{n}=3)$

\begin{tabular}{lccccc}
\hline Dosage form & Label claimed $(\boldsymbol{\mu g})$ & Amount added $(\boldsymbol{\mu g})$ & \% recovered & \% CV & Bias \\
\hline \multirow{3}{*}{ Bulk drug } & 100 & 50 & $99.45 \pm .16$ & 0.156 & -0.55 \\
& 100 & 100 & $99.89 \pm 0.08$ & 0.087 & -0.11 \\
& 100 & 150 & $100.026 \pm 0.29$ & 0.29 & 0.027 \\
\hline \multirow{3}{*}{ Marketed Injection } & 100 & 50 & $95.32 \pm 2.83$ & 2.97 & -4.68 \\
& 100 & 100 & $96.15 \pm 1.62$ & 1.69 & -3.85 \\
& 100 & 150 & $96.68 \pm 2.9$ & 3.0 & -3.32 \\
\hline \multirow{3}{*}{ PLGA NPs } & 100 & 50 & $92.22 \pm 2.8$ & 2.80 & -7.77 \\
& 100 & 100 & $92.89 \pm 1.93$ & 1.93 & -7.11 \\
& 100 & 150 & $94.65 \pm 1.93$ & 1.93 & -5.35 \\
\hline
\end{tabular}

amount after spiking $50 \%, 100 \%$, and $150 \%$ of claimed concentration of bulk drug, the marketed injection and PLGA NPs sample. These samples were analyzed by the proposed method and results were expressed in term of $\%$ recovered, \% CV and bias (Table IV). The \% recovery of epirubicin was obtained in the range of $94.65-100.26 \%$ which was within the acceptance range $80-120 \%$ (ICH, 2005). Thus, method can be said accurate.

\section{Robustness}

Method was also evaluated for its robustness by measuring its capacity to remain unchanged through putting little but intentional variations in method's parameters. Robustness of the method was determined by calculating RSD (\%) of system suitability parameters (Table V) after making deliberate changes in column, column temperature and mobile phase $\mathrm{pH}$, no substantial change was observed in system suitability parameters $(\%$ $\mathrm{RSD}<2$ ) which confirmed the consistency of developed method during normal usage.

TABLE V - Robustness ( $\mathrm{n}=3$ )

\section{Forced degradation studies}

Forced degradation studies were performed to determine the specificity of the analytical method. In this study, the developed method was found able to clearly separate the analyte peak and the degradation products (Table VI). Chromatograms obtained after forced degradation study (acid, base, photo, oxidative, thermal stress) demonstrated separate peaks of analyte and degradants, which indicated the specificity of the developed method. Epirubicin was found to be most resistant to acid treatment while highly sensitive to alkali treatment (Figure 3).

\section{Applications of method}

For the development and optimization of epirubicin loaded PLGA NPs, various formulation parameters like polymer type, polymer concentration, drug-polymer ratio, sonication time, stabilizer type, stabilizer concentration,

\begin{tabular}{lcccc}
\hline & & \multicolumn{3}{c}{ Parameter evaluated } \\
\cline { 3 - 5 } & & $\begin{array}{c}\text { Peak area } \\
\text { (\% RSD) }\end{array}$ & $\begin{array}{c}\text { RT } \\
\text { (\%RSD) }\end{array}$ & $\begin{array}{c}\text { Tailing } \\
\text { (\% RSD) }\end{array}$ \\
\hline Column & $\begin{array}{c}\text { Purosphere }{ }^{\circledR} \\
\text { Supelco }\end{array}$ & 1.26 & 0.209 & 1.26 \\
\hline Temperature & $\begin{array}{l}25^{\circ} \mathrm{C} \\
30^{\circ} \mathrm{C}\end{array}$ & 1.37 & 0.53 & 0.76 \\
\hline $\mathrm{pH}$ & 3.0 & 1.55 & 0.51 & 0.65 \\
\hline
\end{tabular}


TABLE VI - Stress induced degradation studies

\begin{tabular}{lcc}
\hline Stress conditions & $\begin{array}{c}\text { \% Mean } \\
\text { Recovered } \pm \text { SD }\end{array}$ & Figure \\
\hline Untreated Sample & 100 & $4 \mathrm{a}$ \\
$\mathrm{HCl}(0.1 \mathrm{M}) 24 \mathrm{~h}$ & $98.32 \pm 0.87$ & $4 \mathrm{~b}$ \\
$\mathrm{NaOH}(0.1 \mathrm{M}) 24 \mathrm{~h}$ & $0.0 \%$ & $4 \mathrm{c}$ \\
Daylight, 24 h & $90.23 \pm 0.96$ & $4 \mathrm{~d}$ \\
$\mathrm{H}_{2} \mathrm{O}_{2}(30 \%, \mathrm{v} / \mathrm{v}), 24 \mathrm{~h}$ & $87.36 \pm 0.91$ & $4 \mathrm{e}$ \\
Thermal treatment $\left(50{ }^{\circ} \mathrm{C}, 24 \mathrm{~h}\right)$ & $82.16 \pm 1.01$ & $4 \mathrm{f}$ \\
\hline
\end{tabular}

volume of internal aqueous phase etc. were studied to see their effect on the entrapment efficiency and drug loading of NPs. Entrapment efficiency was found to be in the range of $11.5-44.12 \%$ while the drug loading was found to be in the range of $1.13-4.34 \%$.

In-vitro release study of free epirubicin solution showed a very fast release i.e. drug diffused out completely within an hour while epirubicin loaded PLGA NPs demonstrated sustained biphasic release pattern, initially $\sim 20 \%$ of total loaded drug was diffused out in first $2 \mathrm{~h}$ and remaining thereafter i.e. $\sim 85 \%$ in 48 h. Burst effect can be explained by high drug solubility in dissolution media and availability of drug molecules at the surface which leached out rapidly while sustained release can be attributed to existence of drug molecules at the core of hydrophobic polymer matrix.

Epirubicin loaded PLGA NPs demonstrated better permeation profile (Jss $0.63 \mu \mathrm{g} / \mathrm{cm}^{2} . \mathrm{h}$ ) over free drug solution (Jss $0.23 \mu \mathrm{g} / \mathrm{cm}^{2}$.h) across Caco-2 cell line. Similarly, better permeation profile of epirubicin across rat ileum through NPs (Jss $1.0 \mu \mathrm{g} / \mathrm{cm}^{2}$.h) was observed when compared with free solution (Jss, $0.223 \mu \mathrm{g} / \mathrm{cm}^{2} . \mathrm{h}$ ). Significantly high flux across the Caco- 2 cell line and rat ileum $(p<0.001)$ through NPs can be attributed to encapsulation of drug into NPs provided protection to it from P-gp, and CYP-450. In addition, endocytic uptake of particles improved the permeation.

Figure 4 summarizes stability data. Six-month stability profile demonstrated no significant change in assay at both long-term condition, $5 \pm 3{ }^{\circ} \mathrm{C}(\sim 1.8 \%)$ and accelerated storage condition, $25 \pm 2{ }^{\circ} \mathrm{C}, 60 \pm 5 \% \mathrm{RH}$ $(\sim 2.5 \%)$. As per the ICH guidelines (Q1A R2), more than
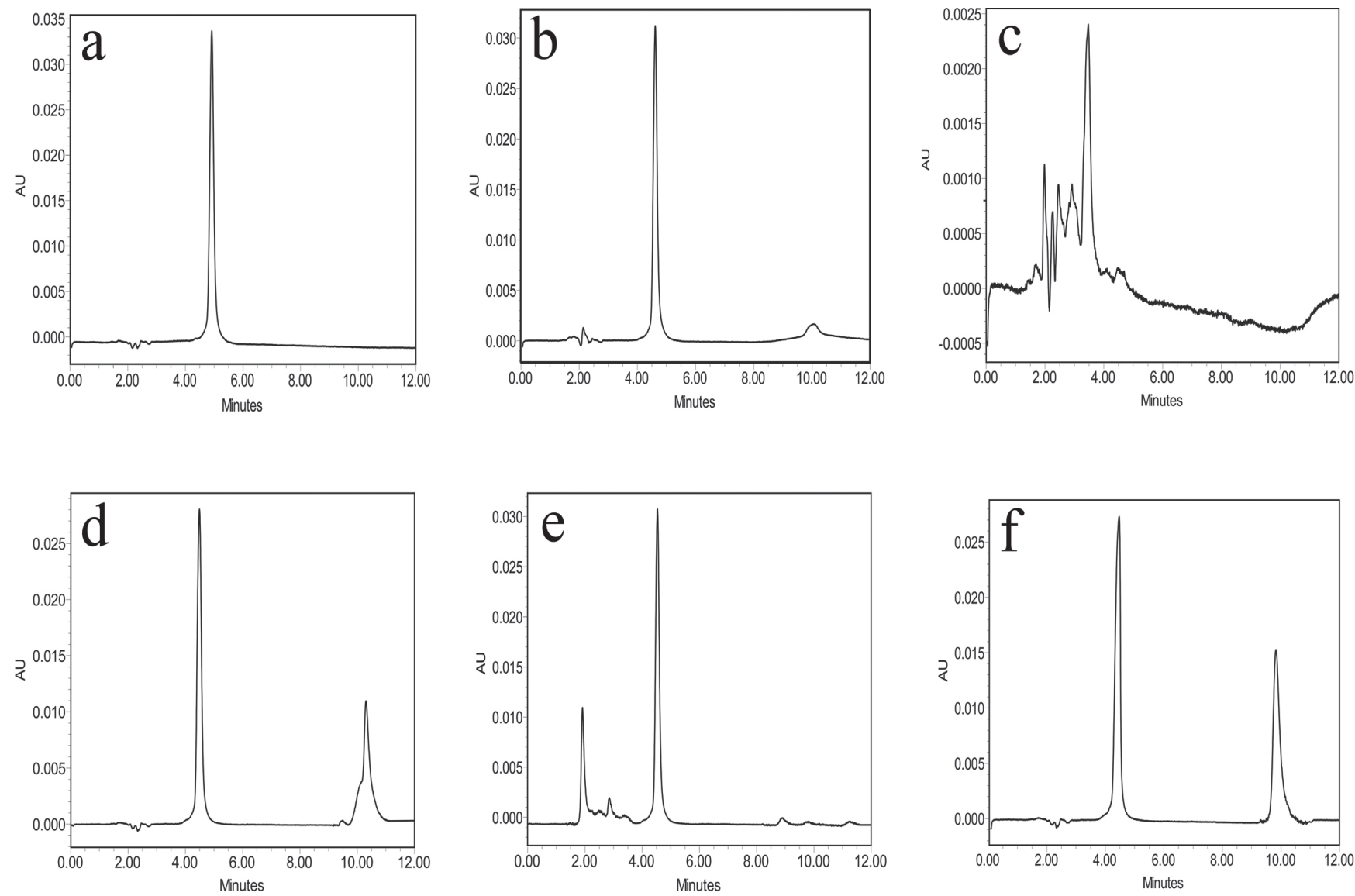

FIGURE 3 - Chromatograms obtained from forced degradation studies; a) Pure epirubicin hydrochloride; b) acid treatment; c) alkali treatment; d) Photo treatment; e) Oxidative treatment; f) Thermal treatment. 


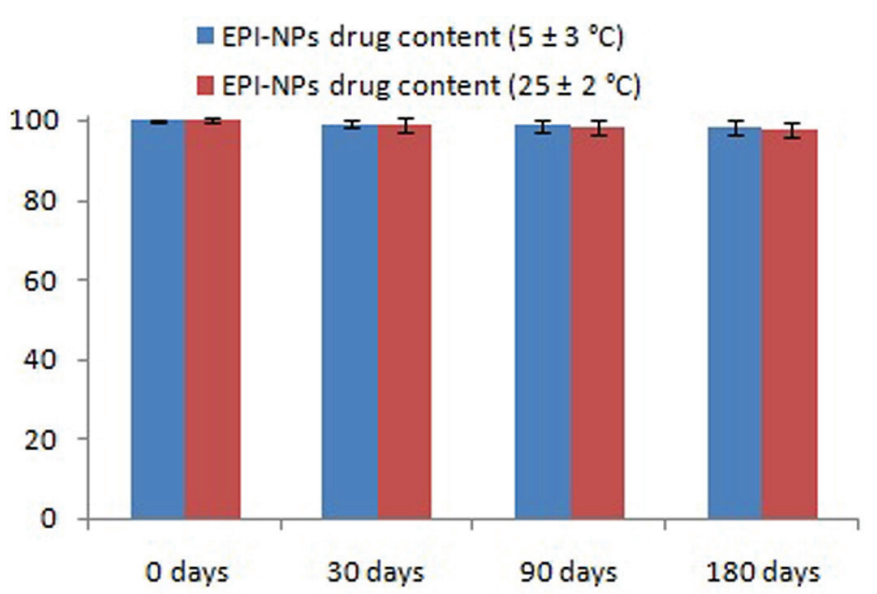

FIGURE 4 - Change in drug content into the EPI-NPs after storage at normal condition $\left(5 \pm 3{ }^{\circ} \mathrm{C}\right)$ and accelerated condition $\left(25 \pm 2{ }^{\circ} \mathrm{C}\right)$.

$5 \%$ change in assay is considered "significant" at any sampling point during 6 months at accelerated conditions (ICH, 2003). Thus, formulation can be considered stable.

\section{CONCLUSION}

A simple and sensitive HPLC method for the quantitative estimation of epirubicin was successfully developed. Statistical assessment of methods proved that the developed method is specific, precise, and accurate and can be used successfully for the quantitative estimation in bulk drug, marketed formulation and polymeric nanoparticles for routine quality control of said dosage form. Stress induced degradation studies disclose the suitability of method for the quantification of drugs in the presence of degradants. The developed method has been successfully applied for the estimation of drug loading, entrapment efficiency, in vitro release profile, in vitro permeation profile and stability of the developed polymeric nanoparticles.

\section{ACKNOWLEDGEMENT}

Authors are thankful to Jamia Hamdard, for facilitating research activities and Department of Biotechnology (DBT) for financial support. Authors also acknowledge the contribution of Fresenius Kabi and Evonik Degussa Pvt. Ltd. for providing gift samples.

\section{REFERENCES}

Badea I, Lazar L, Moja D, Nicolescu D, Tudose A. A HPLC method for the simultaneous determination of seven anthracyclines. J Pharm Biomed Anal. 2005;39(1-2):305-309.
Dine T, Brunet C, Luyckx M, Cazin M, Gosselin P, Cazin JL. Rapid quantitative determination of epirubicin and its metabolites in plasma using high performance liquid chromatography and fluorescence detection. Biomed Chromatogr BMC. 1990;4(1):20-23.

Dodde WI, Maring JG, Hendriks G, Wachters FM, Groen HJ, de Vries EG, et al. Determination of epirubicin and its metabolite epirubicinol in saliva and plasma by HPLC. Ther Drug Monit. 2003;25(4):433-40.

International Conference on Harmonisation. ICH-HarmonisedTripartite-Guideline: stability testing of new drug substances and products Q1A R2, Revised a second time and has reached Step 4 of the ICH Process at the ICH Steering Committee meeting on 6 February; 2003.

International Conference on Harmonisation. ICH-harmonisedtripartite-guideline: validation of analytical procedures: text and methodology, Q2 (R1), Geneva; http://www.ich.org/ LOB/media/MEDIA417.pdf, 2005 (Parent Guideline dated 27 October 1994, Complementary Guideline on Methodology dated 6 November 1996 incorporated in November 2005). 2005.

Kurbanoglu S, Palabiyik BB, Gumustas M, Şanl S, Uslu B, Ozkan SA. Development and validation of a stability-indicating RP-LC method for the determination of anticancer drug epirubicin in pharmaceuticals. J Liq Chromatogr Rel Technol. 2013;37(11):1583-96.

Neil O. The Merck Index, an Encyclopedia of Chemicals Drug and Biologicals. 14 $4^{\text {th }}$ ed. White House Station, NJ: Merck Research Laboratories, Division of Merck and Co. Inc.; 2006.

Ormrod D, Holm K, Goa K, Spencer C. Epirubicin: a review of its efficacy as adjuvant therapy and in the treatment of metastatic disease in breast cancer. Drugs Aging. 1999;15(5):389-416.

Ricciarello R, Pichini S, Pacifici R, Altieri I, Pellegrini M, Fattorossi A, et al. Simultaneous determination of epirubicin, doxorubicin and their principal metabolites in human plasma by high-performance liquid chromatography and electrochemical detection. J Chromatogr B Biomed Sci Appl. 1998;707(12):219-25.

Sottani C, Leoni E, Porro B, Montagna B, Amatu A, Sottotetti F, et al. Validation of an LC-MS/MS method for the determination of epirubicin in human serum of patients undergoing drug eluting microsphere-transarterial chemoembolization (DEMTACE). J Chromatogr B Anal Technol Biomed Life Sci. 2009;877(29):3543-48. 
Developed and validated stability indicating HPLC method for the determination of epirubicin in bulk drug, marketed injection and polymeric nanoparticles

Sweetman S, Martindale C. The Extra Pharmacopoeia. $33^{\text {rd }}$ ed. London, UK: Pharmaceutical Press; 2007.

Tariq M, Alam MA, Singh AT, Iqbal Z, Panda AK, Talegaonkar S. Biodegradable polymeric nanoparticles for oral delivery of epirubicin: In vitro, ex vivo, and in vivo investigations. Colloids Surf B Biointerfaces. 2015a;128:448-56.

Tariq M, Iqbal Z, Ali J, Baboota S, Parveen R, Mirza M, et al. Development and validation of a stability-indicating high-performance thin-layer chromatographic method for the simultaneous quantification of sparfloxacin and flurbiprofen in nanoparticulate formulation. J Planar Chromatogr Modern TLC. 2014;27(2):124-31.

Tariq M, Negi LM, Talegaonkar S, Ahmad FJ, Iqbal Z, Khan AM. Chromatographic method for irinotecan estimation: screening of P-gp modulators. Ind J Pharm Sci. 2015b;77(1):1423.
Wall R, McMahon G, Crown J, Clynes M, O’Connor R. Rapid and sensitive liquid chromatography-tandem mass spectrometry for the quantitation of epirubicin and identification of metabolites in biological samples. Talanta. 2007;72(1):145-54.

Warsi MH, Jain GK, Pathan SA, Chander P, Singh AK, Talegaonkar S, et al. Aqueous humor pharmacokinetics of dorzolamide loaded PLGAChitosan nanoparticles by ultra performance liquid chromatography. Curr Pharm Anal. 2011;7(3):189-94.

Received for publication on $01^{\text {st }}$ September 2017 Accepted for publication on $04^{\text {th }}$ April 2018 